Titulo do Trabalho

\title{
GESTÃO DE PILHAS E BATERIAS USADAS ESCOLA POLITÉCNICA DA USP
}

Nome da Autora Principal

WELSON Gonçalves Barbosa Junior

Nomes dos Co-autores

Vanderley Moacyr John; José Carlos Miezwa; Eduardo Gurzoni; Raphael Rodrigues

Nome do Orientador

Instituição

Instituição de Fomento

E-mail de contato

Palavras-chave

\section{Objetivo}

Sistematizar o processo de "Gestão de Pilhas e Baterias" utilizadas nas dependências da Escola Politécnica da Universidade de São Paulo, atendendo as diretrizes da Escola, da Universidade, as leis ambientais e causar impactos ambientais positivos com a diminuição de contaminação do meio-ambiente, estabelecendo oportunidades para que o público politécnico seja informado 
corretamente sobre os males causados pelo descarte incorreto de resíduos e como devemos proceder para evitar que metais pesados como chumbo, cádmio e mercúrio e seus compostos, sejam dispostos no meio ambiente..

\section{Metodologia}

- Discussão com a Diretoria da Escola e com os departamentos envolvidos.

- Criação de:

- Comissão "Poli Recicla" composta por dois docentes, dois funcionários e dois discentes indicados pela Diretoria da Escola

- Subcomissão de Zeladores e Administrador (sete zeladores e um administrador).

- Reuniões periódicas com todos os envolvidos para melhoria do processo.

- Identificação da necessidade de pontos de coleta em cada um dos oito prédios;

- Qualificação de Fornecedores.

- Equipamento de coleta

- EPI's

- Destinação Final

- Compra e instalação de dois tipos de coletor em cada prédio, facilitando o trabalho de destinação e coleta e o armazenamento temporário:

- 8 coletores com capacidade para $40 \mathrm{~kg}$ e com bocal apropriado para pilhas e baterias de pequeno e médio portes, tipos "AAA", "AA", "C" e "D" (Norma ANSI-USA), inclusive de "Lítio" e de "Botão"..

- 8 coletores com capacidade para $100 \mathrm{~kg}$ e com o bocal apropriado para pilhas e baterias não suportadas pelos coletores menores.

- 2 Coletores com capacidade para $500 \mathrm{~kg} / \mathrm{unidade}$, que suportam o armazenamento de, até, uma tonelada de pilhas e baterias. 


\section{Periódica Eletranica

- Treinamento:

- Funcionários do Serviço de Manutenção da Escola

- Equipe de Limpeza

- Recepcionistas dos prédios

- Divulgação utilizando-se a ferramenta de "Endomarketing", ou seja Comunicação Interna através do Marketing e vice-versa, atingindo assim todos os politécnicos e comunidade USP;

- Criação de Indicadores;

- Pesagem e destinação final para empresa especializada e licenciada pelos órgãos ambientais.

Periodicidade: inicialmente mensal, após um ano trimestral e a partir do segundo ano semestral.

- Análises periódicas.

\section{Resultados Obtidos}

Os resultados do projeto têm se mostrado muito positivo:

1-) Gestão de Pilhas e Baterias em números:

\begin{tabular}{|c|c|c|c|c|c|}
\hline № de dias & $\mathbf{K g}$ & $\begin{array}{c}\text { Média } \\
\text { anual } \\
(\mathbf{k g})\end{array}$ & $\begin{array}{c}\text { Média mensal } \\
\mathbf{( k g )}\end{array}$ & $\begin{array}{c}\text { média } \\
\mathbf{s e m a n a l} \\
(\mathbf{k g})\end{array}$ & $\begin{array}{c}\text { Média diária } \\
\mathbf{( k g )}\end{array}$ \\
\hline 548 & 801,4 & 475,282847 & 44,52222222 & 10,685333 & 1,52647619 \\
\hline \hline
\end{tabular}




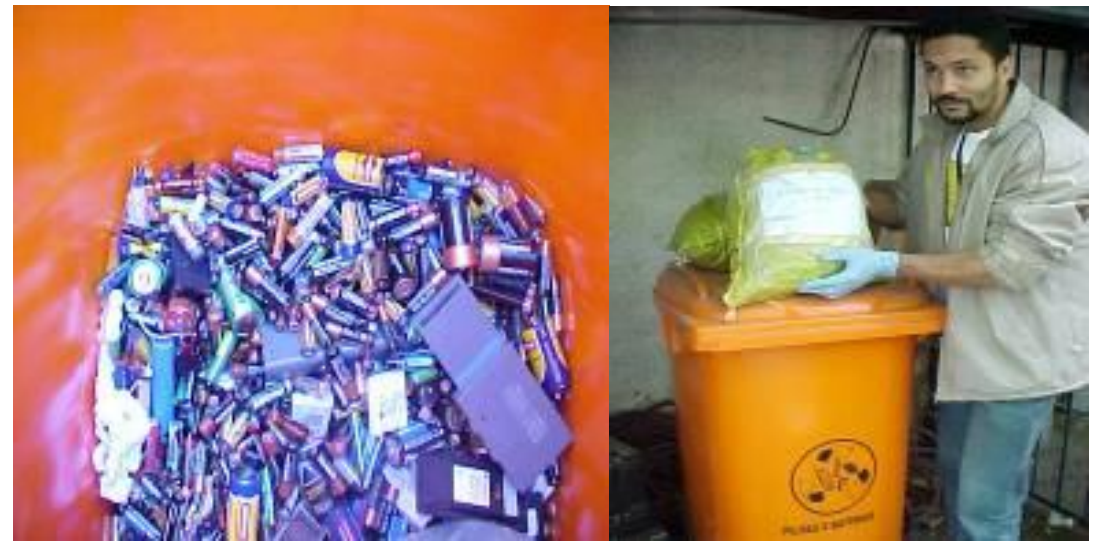

Pilhas e Baterias para descarte Funcionário pesando material

2-) Resíduos gerados externamente:

O programa Poli Recicla inicialmente recolhia Pilhas e Baterias utilizadas na própria escola, mas após considerável demanda abrimos para nossa comunidade (professores, funcionários e alunos) descartarem também o material proveniente de suas casas, trabalhos etc.

Para se ter uma idéia do sucesso desse programa, $43 \%$ das solicitações de informações externas sobre o Poli Recicla são sobre a "Gestão de Pilhas e Baterias".

\section{Conclusões}

Os indicadores evidenciam que o projeto tem apresentado ótima aceitação junto a comunidade politécnica e serve de incentivo para a equipe do Poli Recicla continuar com a sua tarefa de despertar nos professores, funcionários e alunos, além do público externo que nos procuras, a devida atenção para diferentes questões relacionadas aos resíduos. 


\section{Referências}

ADAMS, Ann Patchak, AMOS, C. Kenna. Batteries. In: LUND, Herbert F. Recycling Handbook. New York: McGraw-Hill, 1993.

CONSELHO NACIONAL DE MEIO AMIBENTE. Resolução n. 257 de 30 de junho de 1999 e Resolução n. 401 de 04 de novembro de 2008.

FISHBEIN, Bette. Industry Program to Collect Nickel-Cadmium (Ni-Cd) Batteries [online]. 1998,

RESÍDUOS SÓLIDOS - CETESB http:/WWW.CETESB.SP.GOV.BR

- SITE: http://www.apilhas.com

- Ministério do Meio Ambiente - CONAMA (http://www.mma.gov.br) 